\title{
ERJ
}

Engineering Research Journal

Faculty of Engineering

Minoufiya University

\section{Optimal PI Gains Scheduler for Three Phase Induction Motor Drive Using PSO}

\author{
Hussein M. Wally \\ Assistant Researcher,
} Mechanical \& Electrical Research Center National Water Research Center, Egypt.

Email: Eng.hussein_wally@yahoo.com

\section{Haitham Z. Azazi}

epartment of Electrical Engineering,

Faculty of Engineering,

Menoufiya University, Egypt.

Email: Haitham_azazi@yahoo.com

\author{
Fahmy M. El-Khouly \\ Department of Electrical Engineering, \\ Faculty of Engineering, \\ noufiya University, Egypt. \\ Email:Fahmyel@yahoo.com
}

\begin{abstract}
This paper proposed a Gain-Scheduling Adaptive of a Proportional-Integral (GSAPI) controller scheme for speed control of three-phase induction motor (IM) drives using a particle swarm optimization (PSO) algorithm to optimize the parameters of the proportional-integral (PI) of the speed controller. The PI gains are allowed to vary within a predetermined range and therefore, eliminate the problems faced by the conventional fixed PI and PSO-PI without gain-scheduling control speed controllers. The performance of the proposed GSAPI speed controller is simulated and compared with the conventional fixed PI and PSO-PI speed controllers under different operating conditions. The tuning of PI speed controller parameters is determined by conventional fixed gains, PSO-PI without gain-scheduling control and on-line. For conventional PI, the PI gains are optimized by Trial-and-error method. For PSO-PI tuning, the PI gains are optimized by PSO. On-line application, PSO gains scheduling adaptively adjusts the controller gains to improve the speed response under different operating conditions. The simulation and experimental results show that the GSAPI can be efficiently used for tuning parameters of the PI speed controller, also a good improvement in transient as well as a steady-state response of the proposed controller over the conventional fixed PI and PSO-PI one.

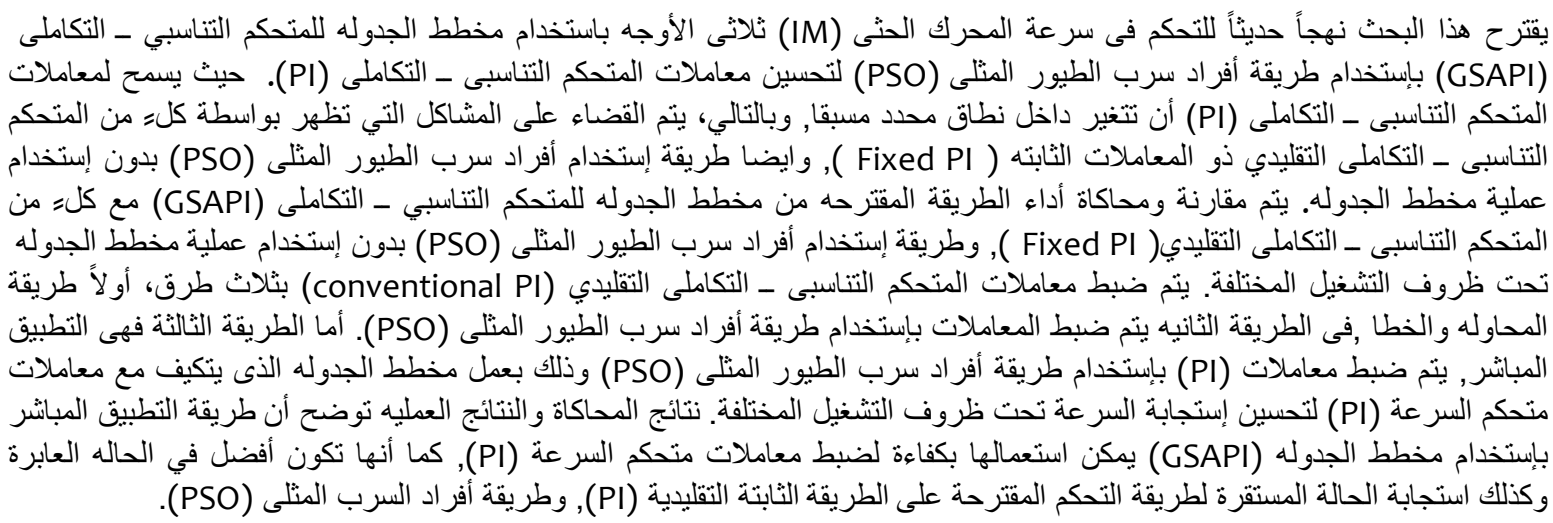
Index Terms, Gain Scheduling Adaptive a PI Controller (GSAPI), Particle Swarm Optimization (PSO), Induction Motor (IM), Proportional-Integral (PI).
\end{abstract}

\section{INTRODUCTION}

IM can be considered as one of the largest consumers of electrical energy due to its well-known advantages, including robustness, reliability, low price and maintenance-free operation. The IMs are used in both industrial and commercial sectors in a wide range of applications, such as fans, compressors, pumps, conveyors, winders, mills, transports, elevators and home appliances [1-3]. Hence, the research potential of the drive is especially towards development of a speed controller, so that performance of the motor is optimized. The optimized gain values are fed to the controller to simulate the drive [4].

It is well known that a conventional PI-controller is most widely used in industry due to its simple control structure, ease of design and low cost. However, the PI type controller cannot give a good control performance. Moreover, it suffers from disadvantages of slower response, larger overshoots, and oscillation [5]. PIcontrollers have been applied to control almost any process in current use, from aerospace to motion control, from slow to fast systems. Alongside this success, however, the problem of tuning PI-controllers has remained an active research area. Furthermore, with changes in system dynamics and variations in operating points, PI-controllers should be returned regularly. This has triggered extensive research on the possibilities and potential of the so-called adaptive PIcontrollers. Loosely defined, adaptive PI-controllers avoid time-consuming manual tuning by providing optimum PI-controller settings automatically as the system dynamics or operating points change [6]. To 
reduce the complexity of tuning PI parameters by the traditional approach, many random search methods i.e. simulated annealing (SA), genetic algorithm (GA), bees' algorithm (BA), ant colony optimization (ACO) and particle swarm optimization (PSO), have recently received much interest for achieving high efficiency and searching global optimal solution [7-13].

Gain scheduling is an alternative to controller parameter adaptation because it has the advantage that the parameters can be changed quickly, and thus, the system can follow rapid changes of the operating conditions. An optimal PID gain-scheduling system for providing faster responses to power requests in hydrogenerator applications was proposed in [14]. A gain-scheduling control system for dc motor drive was presented in [15], genetic fuzzy PID controller based on adaptive gain scheduling for load frequency control was proposed in [16], and an adaptive fuzzy gainscheduling scheme for load frequency control was proposed in [17]. The application of the gainscheduling regulator for high-performance position control of switched reluctance motor drives has been investigated in [18] and based on fuzzy logic control in [19] for obtaining a fast dynamic response over the entire speed range. However, the disadvantage such as designing logic controllers to need expertise of the human expert and determining parameters of the controller by trial-and-error limits its application.

In this paper, a GSAPI controller for three-phase IM drive system using PSO is presented and is to develop a high-performance control system for precise speed control of a three-phase IM drive. It has the advantage that the parameters can be changed quickly, and thus, the system can follow rapid changes of the different operating conditions. The controller parameters are adjusted based on the motor drive operating conditions. The real-time estimation of speed proportional-integral (PI) parameter is accomplished through a nonlinear compensation lookup table that takes into account the influence of load torque, and rotor speeds variation. The proposed GSAPI speed controller gains are allowed to vary within a predetermined range, is characterized by low computational time, ease of implementation and suitable for practical applications, and therefore, eliminate the problem by the conventional PI and PSO-PI without gain-scheduling control speed controllers. Simulation model is established on Matlab/Simulink to test the three-phase IM drive system under different operating conditions. Experimental system was built with dSPACE (DS1104) to examine and assess the performance of the proposed controller. The proposed GSAPI controller is characterized by using PSO with gain scheduling, also is characterized by low computational time, ease of implementation and suitable for practical applications.

The remaining of the paper is organized as follows: in Section II, induction motor model is presented; The Section III, field oriented control of three-phase IM is discussed; A PSO is presented in section IV. Speed control schemes of three-phase IM are discussed in The Section V. Simulation and experimental results are given to demonstrate the advantage of the proposed scheme is described in Section VI and VII, respectively. Conclusion and reference are mentioned in the last section.

\section{INDUCTION MOTOR MODEL}

Squirrel-cage induction motor is represented in its de-qe dynamic model. This model represented in a synchronous reference frame is expressed as follows;

$\left[\begin{array}{c}\mathrm{V}_{\mathrm{qse}}^{\mathrm{e}} \\ \mathrm{V}_{\mathrm{dse}}^{\mathrm{e}} \\ 0 \\ 0\end{array}\right]=\left[\begin{array}{cccc}\mathrm{R}_{\mathrm{s}}+\mathrm{pL}_{\sigma} & \omega_{\mathrm{e}} \mathrm{L}_{\sigma} & \mathrm{p} \frac{\mathrm{L}_{\mathrm{m}}}{\mathrm{L}_{\mathrm{r}}} & \omega_{\mathrm{e}} \frac{\mathrm{L}_{\mathrm{m}}}{\mathrm{L}_{\mathrm{r}}} \\ -\omega_{\mathrm{e}} \mathrm{L}_{\sigma} & \mathrm{R}_{\mathrm{s}}+\mathrm{pL}_{\sigma} & -\omega_{\mathrm{e}} \frac{\mathrm{L}_{\mathrm{m}}}{\mathrm{L}_{\mathrm{r}}} & \mathrm{p} \frac{\mathrm{L}_{\mathrm{m}}}{\mathrm{L}_{\mathrm{r}}} \\ -\mathrm{R}_{\mathrm{r}} \mathrm{L}_{\mathrm{m}} & 0 & \mathrm{R}_{\mathrm{r}}+\mathrm{pL}_{\sigma} & \left(\omega_{\mathrm{e}}-\omega_{\mathrm{r}}\right) \mathrm{L}_{\mathrm{m}} \\ 0 & -\mathrm{R}_{\mathrm{r}} \mathrm{L}_{\mathrm{m}} & -\left(\omega_{\mathrm{e}}-\omega_{\mathrm{r}}\right) \mathrm{L}_{\mathrm{m}} & \mathrm{R}_{\mathrm{r}}+\mathrm{pL}_{\sigma}\end{array}\right]\left[\begin{array}{c}\mathrm{I}_{\mathrm{qs}}^{\mathrm{e}} \\ \mathrm{I}_{\mathrm{ds}}^{\mathrm{e}} \\ \lambda_{\mathrm{qr}}^{\mathrm{e}} \\ \lambda_{\mathrm{dr}}^{\mathrm{e}}\end{array}\right]$

The electromechanical equation is also given by;

$T_{e}-T_{L}=J \frac{d \omega_{r}}{d t}+B \omega_{r}$

where, the electromagnetic torque is expressed as;

$T_{e}=\frac{3}{2} \frac{p}{2} \frac{L_{m}}{L_{r}}\left(I_{q s}^{e} \lambda_{d r}^{e}-I_{d s}^{e} \lambda_{q r}^{e}\right)$

where $\mathrm{V}_{\mathrm{qse}}^{\mathrm{e}}, \mathrm{V}_{\text {dse }}^{\mathrm{e}}$ are $\mathrm{q}$, d-axis stator voltages respectively; $\mathrm{I}_{\mathrm{qs}}^{\mathrm{e}}, \mathrm{I}_{\mathrm{ds}}^{\mathrm{e}}$ are $\mathrm{q}$, d-axis stator current respectively; $\lambda_{\mathrm{qr}}^{\mathrm{e}}, \lambda_{\mathrm{dr}}^{\mathrm{e}}$ are $\mathrm{d}, \mathrm{q}$-axis rotor flux respectively; $R_{s}, R_{r}$ are the stator and rotor resistances per phase, respectively; $\mathrm{L}_{\mathrm{s}}, \mathrm{L}_{\mathrm{r}}$ are the self inductances of the stator and rotor respectively; $\mathrm{L}_{\mathrm{m}}$ is the mutual inductance, $L_{\sigma}$ is the leakage inductance, $\omega_{\mathrm{r}}$ is the rotor speed, $p$ is the differential operator, $T_{e}$ is the electromagnetic developed torque, $\mathrm{T}_{\mathrm{L}}$ is the load torque, $\mathrm{J}$ is the rotor inertia and $\mathrm{B}$ is the rotor damping coefficient [20-22] 


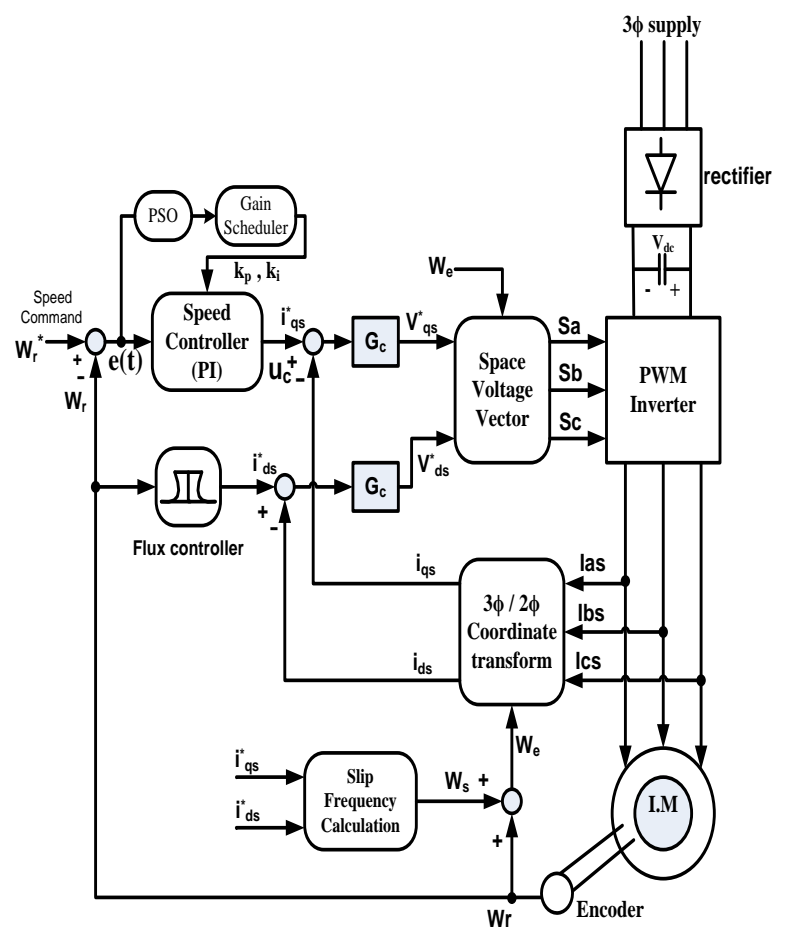

Fig.1 Three-phase IM vector control block diagram with adaptive PI speed controller using PSO

According to the three-phase IM model given above, the block diagram of a speed control for threephase IM vector control with adaptive PSO-PI for speed control loop drive system (on-line) can be represented as shown in Fig.1. The motor parameters are given in appendix.

\section{Field Oriented Control of Three-Phase IM}

In order to achieve high performance, field-oriented control of three-phase IM drive is employed in this paper.

Fig.1 shows a block diagram of an indirect fieldoriented control system for an IM. In this system, the dq coordinate's reference frame is locked to the rotor flux vector rotating at the stator frequency $w_{e}$, and the IM is fed by a current controlled PWM inverter. The motor speed $w_{r}$ is compared to the speed reference $w_{r}^{*}$ and the error is processed by speed controller to produce a torque command $T_{\varepsilon}^{*}$.

The stator quadrature axis current reference $i_{q s}^{*}$ is calculated from torque reference $T_{\Theta}^{8}$ as:

$i_{q s}^{8}=\frac{22}{3 p} \frac{L_{r}}{L_{m}} \frac{T_{\theta}^{8}}{\left|\psi_{r}\right|_{e s t}}$

where, $\left|\psi_{r}\right|_{\text {esst }}=\frac{L_{m} i_{d s}}{1+\tau_{r} s}, \tau_{r}=\frac{L_{r}}{R_{r}}$

where $\tau_{r}$ is rotor time constant.

The stator direct axis current reference $i_{d s}^{8}$ is obtained from rotor flux reference input $\left|\psi_{r}\right|^{*}$.

$i_{d s}^{*}=\frac{\left|\psi_{r}\right|^{8}}{L_{m}}$

Rotor flux position $\theta_{e}$ is generated from slip frequency $w_{S}$, and rotor speed $w_{\mathrm{r}}$.

$\theta_{e}=\int\left(w_{s}+w_{r}\right) d t$

The slip frequency is calculated from the stator reference current $i_{q s}^{8}$ and the motor parameters.

$w_{s}=\frac{L_{m}}{\left\|\psi_{Y}\right\|_{\text {est }}} \frac{R_{Y}}{L_{Y}} i_{q S}^{8}$

where $R_{r}, L_{r}$ and $L_{m}$ are rotor resistance, rotor inductance and mutual inductance respectively, and $\left|\psi_{r}\right|_{\text {est }}$ is estimated rotor flux linkage.

The PI regulator compares the speed set point with the actual mechanical speed of the rotor and produces the stator current quadrature axis reference $i_{q s}^{8}$. The stator current direct axis reference $i_{d s}^{*}$ is usually kept constant at the value required to produce the nominal rotor flux. To operate the motor above its nominal speed a technique known as field weakening is used to reduce the rotor flux. The reference currents are compared with the measured stator currents. The error is used by the PI speed controller to generate the output stator voltages in the direct and quadrature axes. [2326]

\section{Particle SWarm Optimization (PSO)}

PSO is a relatively new evolutionary algorithm that may be used to find optimal solutions to numerical and qualitative problems. PSO was originally developed by James Kennedy and Russell Eberhart in 1995, and emerged from earlier experiments with algorithms that modeled the flocking behavior seen in many species of birds [27].

PSO is well-known and popular search strategy that has gained wide-spread appeal among researchers and has been shown to offer good performance in a variety of application domains, with potential for hybridization (4) and specialization. It is a simple and robust strategy based on the social and cooperative behavior shown by various species like flocks of bird, schools of fish. PSO 
and its variants have been effectively applied to a wide range of real-life optimization problems.

In simulations, birds would begin by flying around with no particular destination and spontaneously formed flocks until one of the birds flew over the roosting area. Due to the simple rules, the birds used to set their directions and velocities, a bird pulling away from the flock in order to land at the roost would result in nearby birds moving towards the roost. Each particle moves about the cost surface at a velocity and tries to modify its position as shown in Fig.2. Each particle represents a candidate solution to the problem. Each particle in search space has a current position $x_{i}$ and a current velocity $v_{i}$. Value of each particle, is determined by fitness function $F(x i)$.

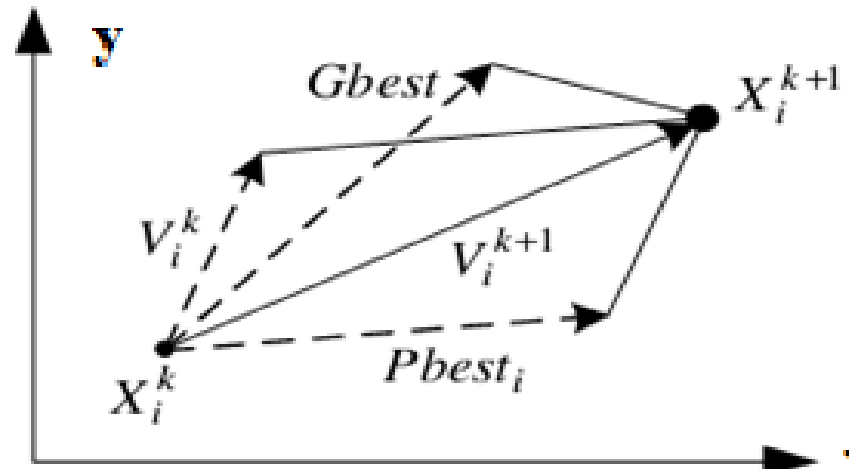

Fig. 2 Concept of modification of a searching point by PSO

In the past several years, PSO has been successfully applied in much research and application areas. It is demonstrated that PSO gets better results in a faster, cheaper way compared.

\section{A. PSO algorithm}

The basic terms used in PSO technique are stated and defined as follows:

1. Particle $X_{i}(i)$ : It is a candidate solution represented by a $\mathrm{k}$-dimensional real-valued vector, where $\mathrm{k}$ is the number of optimized parameters. At iteration $i$, the $j^{\text {th }}$ particle $X(i, j)$ can be described as:

$$
X_{\mathrm{i}}(i)=\left[X_{j 1}(i) ; X_{j 2}(i) ; \ldots . . X_{j k}(i) ; \ldots . . X(i)_{j d}\right]
$$

where, $X^{\prime} s$ are the optimized parameters and $\mathrm{d}$ represents the number of control variables

2. Population: It is basically a set of $\mathrm{n}$ particles at iteration $i$.

pop $(i)=\left[X_{1}(i), X_{2}(i), \ldots \ldots X_{n 1}(i)\right]^{T}$

where, $\mathrm{n}$ represents the number of candidate solutions.
3. Particle velocityV (i): Particle velocity is the velocity of the moving particles represented by a ddimensional really valued vector. At iteration $i \bar{i}$, the $i^{\text {th }}$ particle $V_{j}(i)$ can be described as:

$V_{j}(i)=\left[V_{j 1}(i) ; V_{j 2}(i) ; \ldots \ldots V_{j k}(i) ; \ldots . . V_{j d}(i)\right]$

where $V_{j k}(i)$ is the velocity component of the $j^{\text {th }}$ particle with respect to the $k^{\text {th }}$ dimension.

4. Inertia weight $w(i)$ : It is a control parameter, which is used to control the impact of the previous velocity on the current velocity. Hence, it influences the trade-off between the global and local exploration abilities of the particles. For the initial stages of the search process, large inertia weight to enhance the global exploration is recommended while it should be reduced at the last stages for better local exploration. Therefore, the inertia factor decreases linearly from about 0.9 to 0.4 during a run. In general, this factor is set according to the following equation:

$\omega=\omega_{\max }-\frac{\omega_{\max }-\omega_{\min }}{\text { iter }_{\max }} \times$ iter

where $\omega_{\max }$ and $\omega_{\min }$ are initial and final weights respectively, iter is current iteration number and iter $_{\max }$ is the maximum iteration number. The model using Equation (12) is called 'inertia weights approach (IWA)'

5. Individual best $X^{*}(i)$ : When particles are moving through the search space, it compares its fitness value at the current position to the best fitness value it has ever reached at any iteration up to the current iteration. The best position that is associated with the best fitness encountered so far is called the individual best $X^{*}(i)$.

For each particle in the swarm, $X^{*}(i)$ can be determined and updated during the search.

For the $j^{\text {th }}$ particle, individual best can be expressed as:

$X_{i}(i)=\left[X_{j 1}^{*}(i) ; X_{j 2}^{*}(i) ; \ldots \ldots X_{j d}^{*}(i)\right]$

In a minimization problem with only one objective function $\mathrm{f}$, the individual best of the $j^{\text {th }}$ particle $X_{j}^{*}(i)$ (9) is updated whenever $f\left(X_{j}{ }^{*}(i)\right)<f\left(X_{j}{ }^{*}(i-1)\right)$. Otherwise, the individual best solution of the $j^{\text {th }}$ particle will be kept as in the previous iteration.

6. Global best $X(t)$ : Global best is the best position among all of the individual best positions (10)hchieved so far. 
7. Stopping criteria: Termination of the search process will take place whenever one of the following criteria is satisfied:

- The number of the iterations since the last change of the best solution is greater than a specified number.

- The number of iterations reaches the maximum allowable number.

The particles are manipulated according to the following equations:

$V_{j d}=V_{j d}+c_{1} r_{1}\left(P_{j d}-X_{j d}\right)+c_{2} r_{2}\left(P_{g d}-X_{j d}\right)$

$X_{j d}=X_{j d}+V_{j d}$

(15)

where, $\mathrm{g}$ is the best particle among all particles, $c_{1}$ and $c_{2}$ are positive constant and $r_{1}$ and $r_{1}$ are uniformly distributed numbers in $(0,1)$.

\section{B. Advantages of PSO}

Many advantages of PSO over other traditional optimization techniques can be summarized as follows:

PSO is a population-based search algorithm. This property ensures PSO to be less susceptible in being trapped on local minima. PSO makes use of the probabilistic transition rules and not deterministic rules. Hence, PSO is a kind of stochastic optimization algorithm that can search for a complicated and uncertain area. This makes PSO more flexible and robust than conventional methods. PSO can easily deal with non-differentiable objective functions because PSO uses payoff (performance index or objective function) information to guide the search in the problem space. Additionally, this property relieves PSO of assumptions and approximations, which are often required by traditional optimization models. PSO has the flexibility to control the balance between the global and local exploration of the search space. This unique feature of a PSO overcomes the premature convergence problem and enhances the search capability which makes it different from Genetic Algorithm (GA) and other heuristic algorithms [27-30].

\section{Parameter settings for the PSO algorithm}

The proposed PSO based approach was implemented using Intel core i3. $1.0 \mathrm{GHz}$ processor with 4 GB of RAM in MATLAB 10.0. Initially, several runs have been done with different values of the PSO key parameters such as inertia weight and the maximum allowable velocity. Other parameters are selected as a number of particles $n=30$, the iterations
$=150, w(i)$ varied between $(0.9-0.4)$ and the cognitive and the social parameters $c_{1}$ and $c_{2}$ which are be equalized $\left(c_{1}=c_{2}=2\right)$, and $r_{1} \& r_{2}$ are random numbers uniformly distributed within (0-1).

\section{SPEEd CONTROL SCHEMES OF THREe-PHASE IM}

A general closed-loop of speed controller configuration under our consideration is composed of a motor-load system; a conventional fixed PI speeds controller, PSO-PI without gain-scheduling control and PSO-PI for gains scheduling (on-line) as depicted in Figs.3.

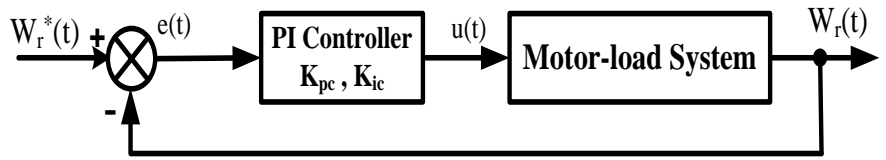

(a)
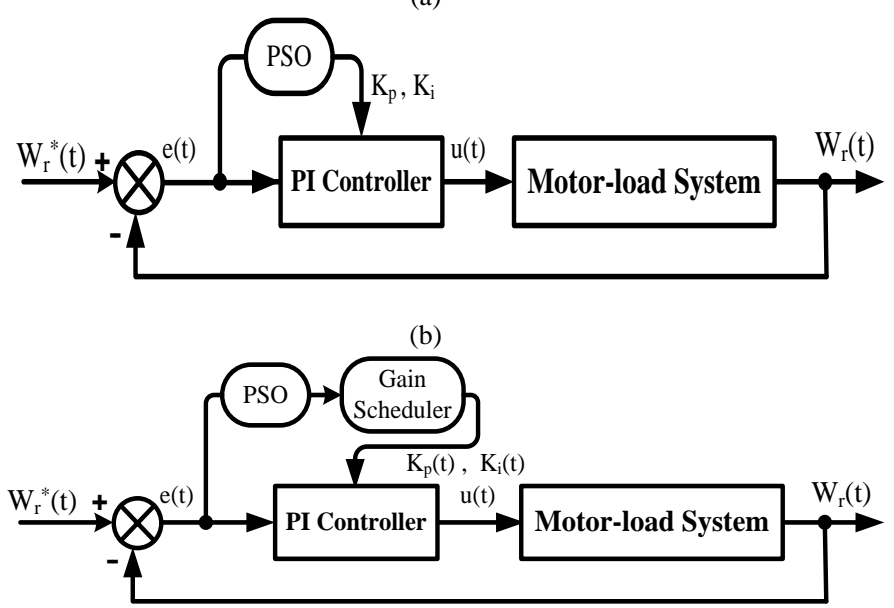

(c)

Fig.3. Description of speed controller for:

(a) A conventional fixed PI speed controller,

(b) PSO-PI without gain-scheduling control (off-line),

(c) GSAPI speed controller (on-line).

\section{A. Conventional Fixed PI Speed Controller}

A PI speed controller has been adopted to provide quick transient response and to ensure zero steady-state error. The conventional fixed PI speed controller can be constructed as shown in Fig.3a and follows [31]:

$u_{c}(t)=K_{p c} e(t)+K_{i c} \int e(t) d t$

where $e(t)$ is the speed error, $e(t)=w_{r}^{*}(t)-w_{r}(t)$. The PI speed controllers gains $K_{p c}$ and $K_{i c}$ are the proportional and the integral constant gains, respectively, these are tuned at rated conditions and have these values along with the different operating conditions. 


\section{B. Particle Swarm Optimization (PSO)}

PSO is suggested by Eberhart and Kennedy in 1995 based on the analogy of swarm of bird and school of fish as mentioned before. The PSO mimics the behavior of individuals in a swarm to maximize the survival of the species. The main advantages of the PSO algorithm over other heuristic optimization techniques are summarized as; simple concept, easy implementation, robustness to control parameters, computational efficiency, lower sensitivity to the nature of the objective function and derivative free property unlike many conventional techniques as shown in Fig.3b [30]. An optimal control scheme based PSO Algorithm method is used for tuning the parameters of PI controller. The PSO algorithm is used to search an optimal parameter set containing $K_{p}$ and $K_{i}$. The parameters used for tuning the PSO algorithm and Simulink parameters are tabulated in Table. 3 and in section IV(C) mentioned above [32].

\section{Gain Scheduling Adaptive PI Controller [GSAPI]}

Gain scheduling method is applied to three-phase IM for online tuning of the PI speed controller in presence of set point changes which obtaining the parameter of the speed controller gains using PSO optimization. It is counted as an adaptive method and offers a robust performance. The structure of this method has the ability of online tuning of the proposed PI with respect to time. It is also robust in presence of system uncertainties [33].

In this study, PI gain scheduling model structure is offered as shown as in Fig.3c by using PSO techniques. GSAPI used to solve the problems of other tuning methods, in order to meet the control objectives and to provide high performance of the drive.

The key feature of the proposed gain scheduling scheme of adaptive control is the reduced amount of computation. An easy and low cost practical implementation of the procedure is possible without employing expensive dedicated computing systems. This scheme is very easy to implement in practice since an existing PI speed controller is tuned automatically to control fast transient recovery and low overshoot in the dynamic response of the system. In this scheme, the gains are allowed to vary over a predetermined range for varying operating conditions. The gain scheduled PI speed controller output, which is considered as the reference torque of the motor can be described as:

$T^{*}(t)=K_{p}(t) e(t)+K_{i}(t) \int e(t) d t$ where $K_{p}(t)$ and $K_{i}(t)$ are the proportional and the integral variable gains, respectively. These gains are obtained by using PSO techniques.

\section{SIMULATION RESULTS}

The control algorithm of the control methods has been developed and simulated using the MATLAB/SIMULINK software based on the introduced mathematical model. The performance of the three-phase IM drive system is tested under different operating conditions. Simulation results include starting operation, step speed command, speed reversal and load impact. The performance of a gainscheduling adaptive of a PI speed controller in comparison with conventional fixed PI and PSO-PI speed controllers is examined and assessed by computer simulations. The system parameters are reported in appendix.

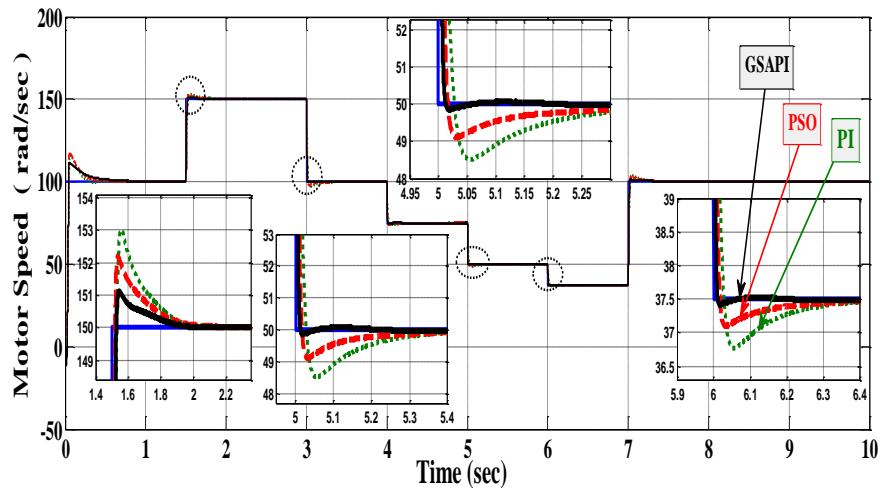

(a)

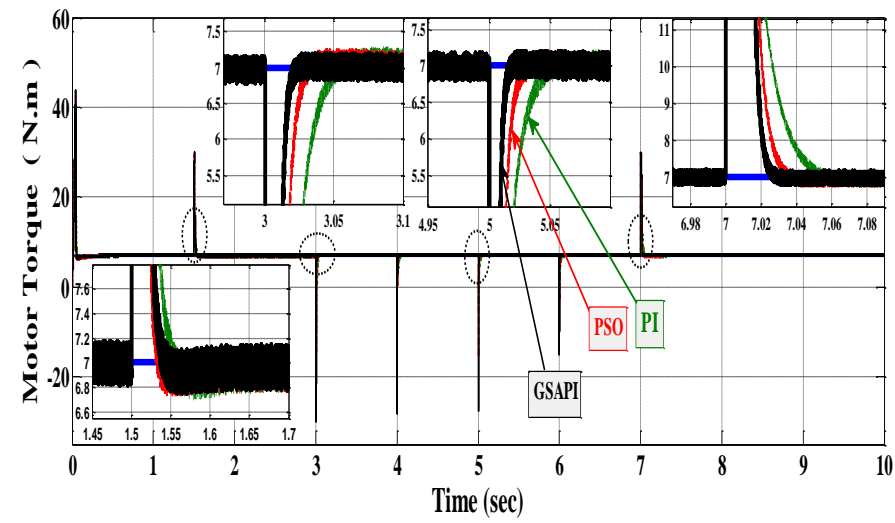

(b) 


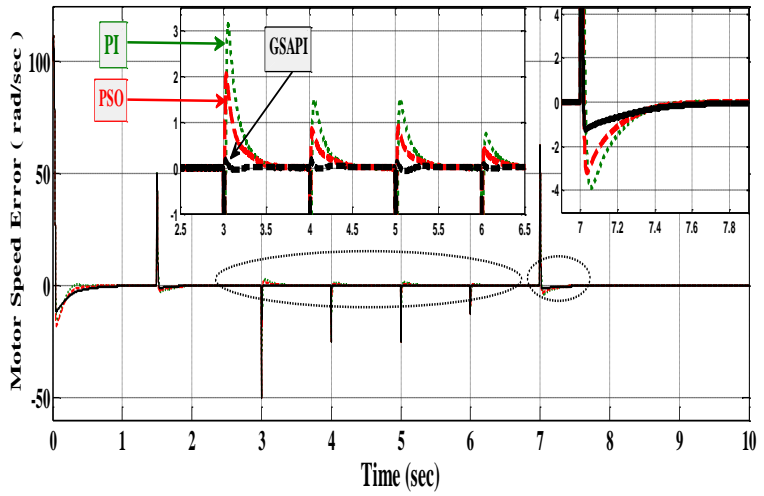

(c)

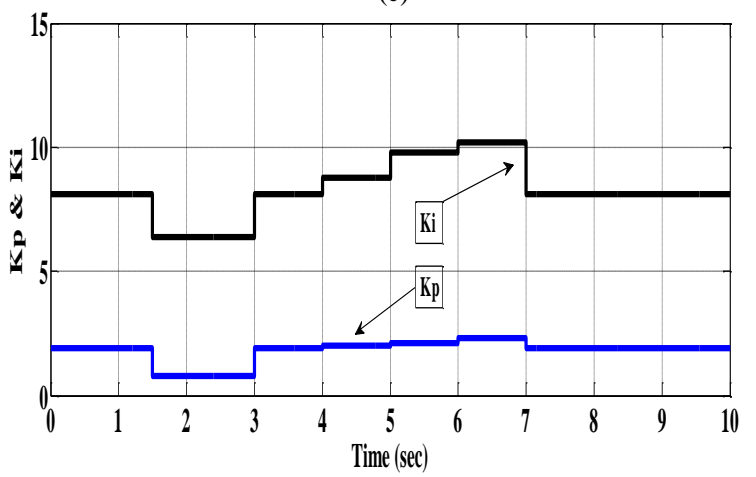

(d)

Fig.6 Simulation response during step speed changes: (a) Motor Speed, (b) Motor Torque, (c) Motor Speed Error, (d) Variation of Kp and Ki for GSAPI.

\section{A. Step Speed Changes}

The three-phase IM drive system is tested under different speed controllers at full load torque. Fig.6 shows the simulated speed responses under conventional fixed PI, PSO-PI and GSAPI speeds controllers. Fig.6a shows the reference and actual speeds under step speed change. It is obvious that the speed response with fixed PI speed controller and PSOPI suffer from overshoots and large settling time in comparison to the GSAPI speed controller. It is also noted that there is no steady-state error in the speed response throughout the operation when GSAPI is activated as shown in Fig.6c. Furthermore, no oscillation in the torque response before it finally settles as shown in Fig.6b.

Fig.6d shows the variations of $K_{p}(t)$ and $K_{i}(t)$ for starting and step speed changes for (GSAPI) at full load torque, and step speed changes.

\section{(b) Speed Reversal}

The stability and synchronization of the drive system with the different controllers are examined during speed reversal. It is evident that the proposed controller as shown in Fig.7 gives a good performance in comparison with the conventional PI and PSO-PI without gain-scheduling control speed controllers. Fig.7a shows the reference and measured speeds under speed reversal. Clearly, the GSAPI speed controller exhibits superior performance in comparison with fixed PI and PSO-PI speed controllers, which suffer from overshoots and large settling time. We can notice that speed response of GSAPI has a minimum overshoot, minimum undershoot, which could be neglected and settles faster in comparison with two other controllers. It is also noted that there is no steady-state error in the speed response throughout the operation when GSAPI is activated as shown in Fig.7c.

Fig.7d shows the variations of $K p(t)$ and $K i(t)$ for starting, and speed changes for GSAPI at full load torque and speed reversal.

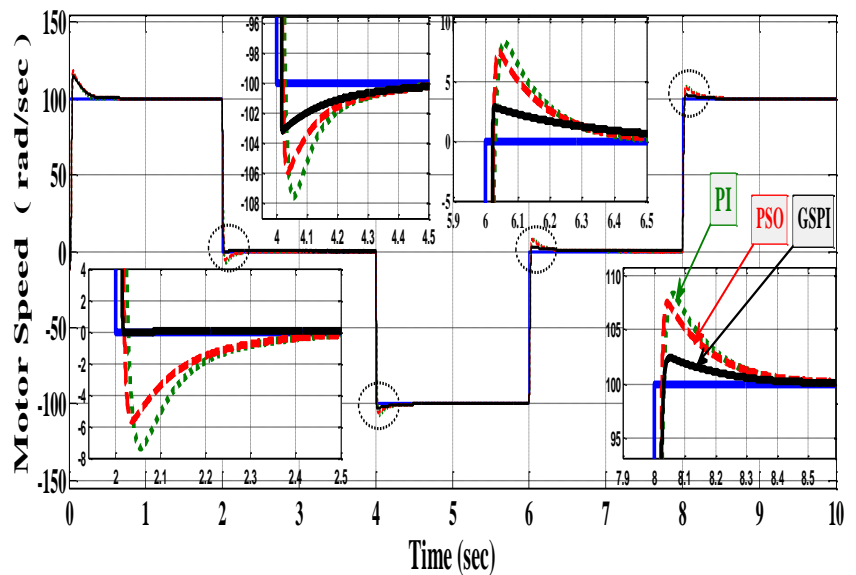

(a)

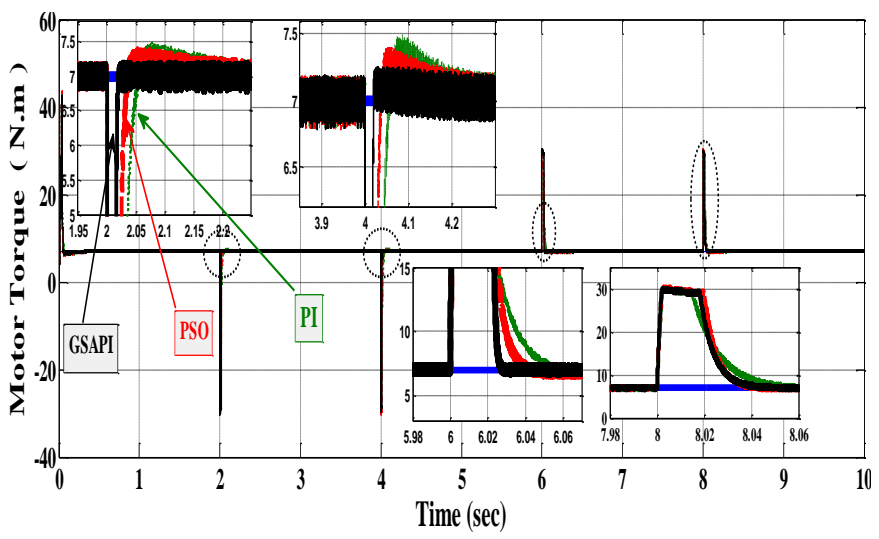

(b) 


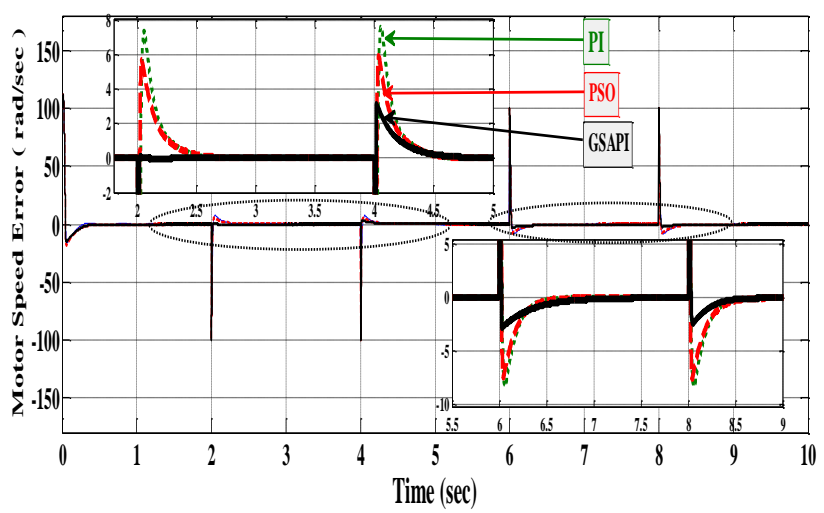

(c)

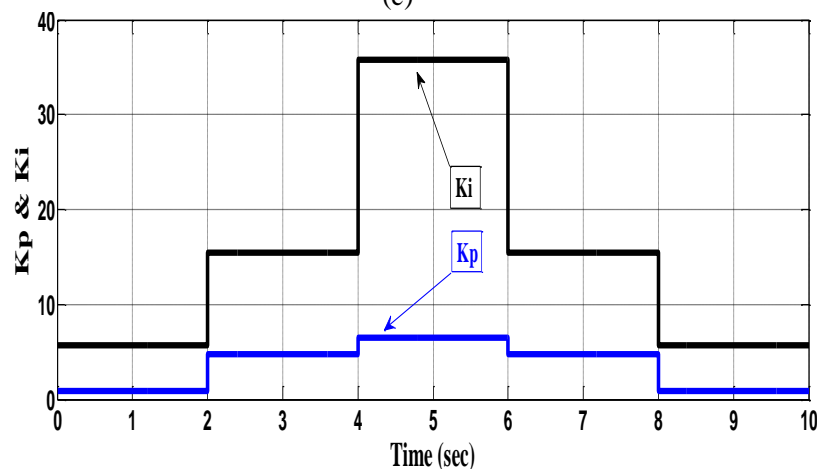

(d)

Fig.7 Simulation response during speed reversal: (a) Motor Speed, (b) Motor Torque, (c) Motor Speed Error, (d) Variation of Kp and Ki for GSAPI.

\section{Load torque disturbances}

The superiority of the GSAPI controller is proven and confirmed under load torque disturbance. Fig.8a shows the speed response of the three-phase IM drive system with command speed at $100 \mathrm{rad} / \mathrm{sec}$, when load torque reference changes as shown in Fig.8b from no load to full load. It is observed that the speed recovers quickly, and the speed dip is low with GSAPI speed controller, which is not the case with fixed PI and PSOPI speed controllers. It is obvious that these gains are adjusted to proper values during different operating conditions of the motor to give a fast dynamic response without steady-state error and takes a minimum rise time to reach the steady-state value as in Fig.8c.

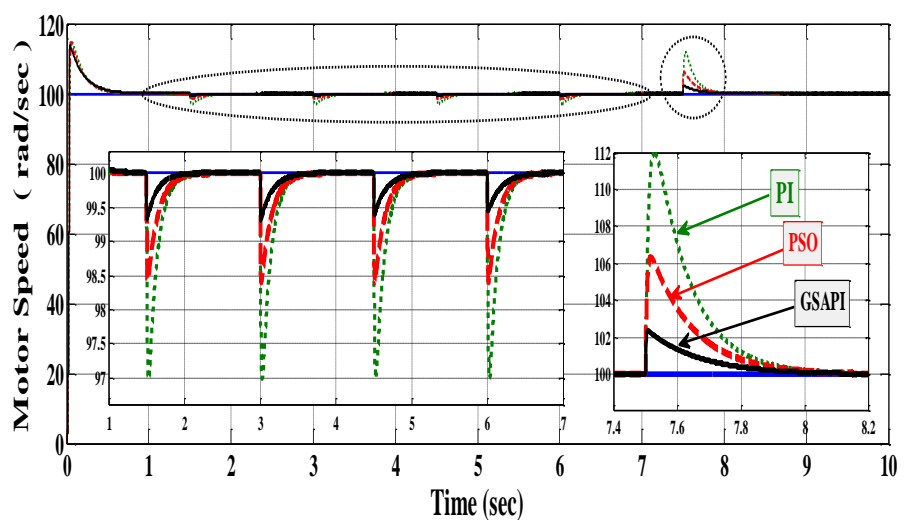

(a)

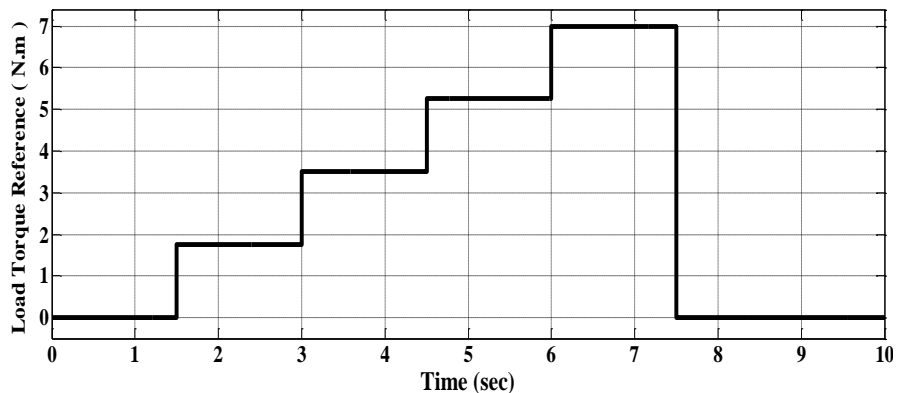

(b)

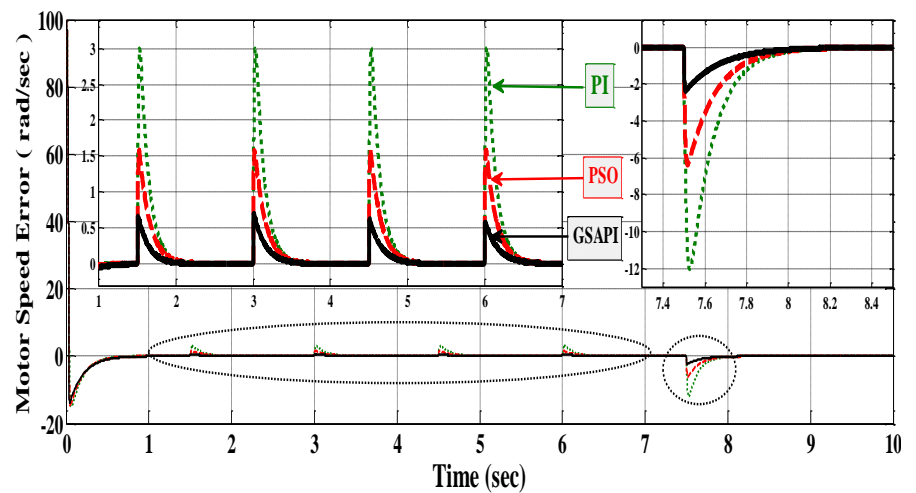

(c)

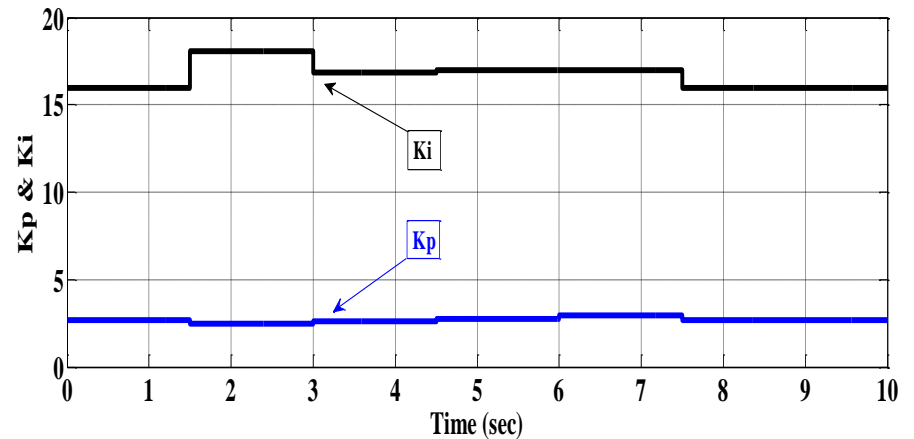

(d)

Fig.8 Simulation response during Load torque disturbances: (a) Motor Speed (b) Load Torque Reference, (c) Motor Speed Error, (d) Variation of Kp and Ki for GSAPI. 
Fig.8d shows the variations of $K_{p}(t)$ and $K_{i}(t)$ for starting, transient conditions and load disturbance for GSAPI at speed constant.

It is noted that, overall dynamic performances of the motor when operated at the GSAPI speed controller with PSO is better than the conventional PI and PSO-PI speed controllers, and the steady-state error of speed response is zero. Simulation results indicate that controllers designed using PSO approach guarantees good performance under various load conditions.

\section{EXPERIMENTAL RESULTS}

With the objective of evaluating the employed topology, a laboratory prototype is setup. The block diagram of the experimental setup and a real view of the complete control system under different operation conditions are shown in Figs.9 and 10 , respectively. The main components of the system which labeled as in Fig.10 are listed in Table 1. The proposed tuning of the speed controller in three-phase IM drives using GSAPI control is done on a digital signal processor board dSPACE(DS1104) plugged into a computer. The control algorithm is executed by 'Matlab/Simulink', and downloaded to the board through host computer. The output of the board is logic signals, which is fed to IGBT through driver and isolation circuits.

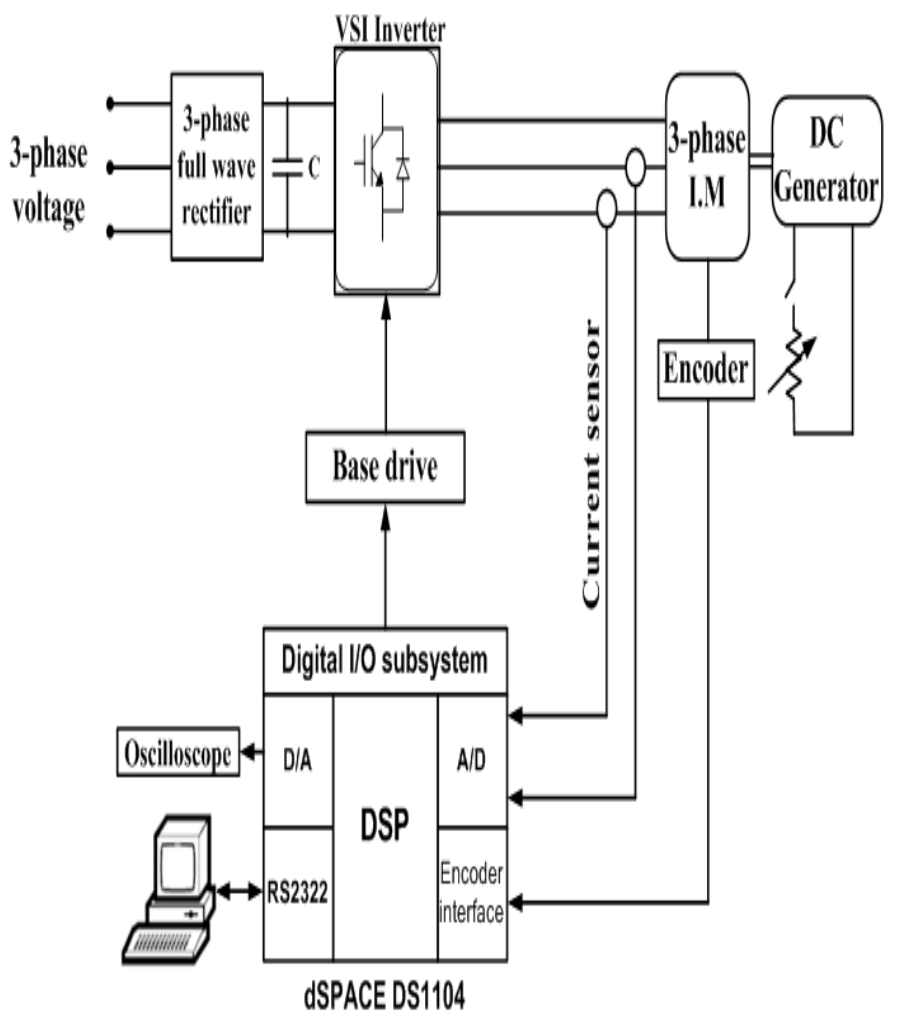

Fig.9 Hardware schematic diagram for the experimental implementation of a.c drive system

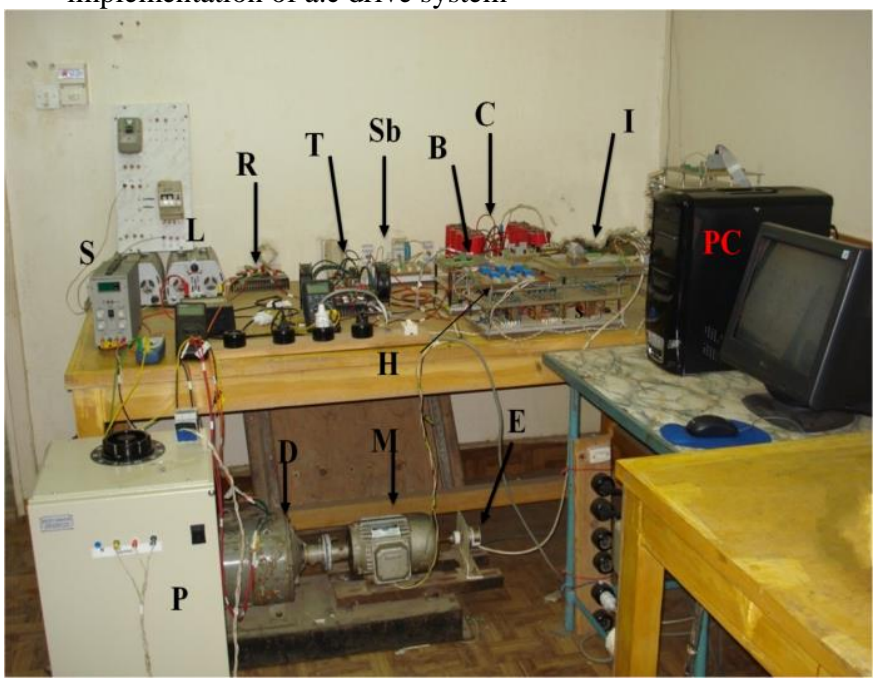

Fig.10 Experimental setup of the a.c drives system 
Table 1

\begin{tabular}{|c|c|c|c|}
\hline Label & Component & Label & Component \\
\hline $\mathrm{M}$ & Induction motor & $\mathrm{D}$ & DC machine \\
\hline $\mathrm{T}$ & $\begin{array}{c}\text { IGBT inverter } \\
\text { module }\end{array}$ & $\mathrm{L}$ & $\begin{array}{c}\text { Variable } \\
\text { resistance }\end{array}$ \\
\hline $\mathrm{B}$ & Base Drive Circuit & $\mathrm{E}$ & Incremental encoder \\
\hline $\mathrm{H}$ & Measurement Circuit & $\mathrm{C}$ & DC link capacitors \\
\hline $\mathrm{I}$ & Interface circuit & $\mathrm{PC}$ & personal computer \\
\hline $\mathrm{S}$ & $\begin{array}{c}\text { All other power } \\
\text { suppliers }\end{array}$ & $\mathrm{P}$ & $\begin{array}{c}\text { Variable AC } \\
\text { power supply }\end{array}$ \\
\hline $\mathrm{R}$ & Rectifier & $\mathrm{Sb}$ & Snubber circuit \\
\hline
\end{tabular}

A. Conventional Fixed PI controller with hand tuning gains (Trial and Error)

The experimental results of motor speed and motor speed error in case of using conventional fixed PI controller with hand tuning gains are shown in Fig.11. It is illustrated from this figures that have zero steadystate error when operating. Nevertheless, the disadvantage of this PI controller is the occurrence of overshoot while speed change from 100 to $120 \mathrm{rad} / \mathrm{sec}$ and from 120 to $140 \mathrm{rad} / \mathrm{sec}$, undershoot while speed change from upper to under change again.

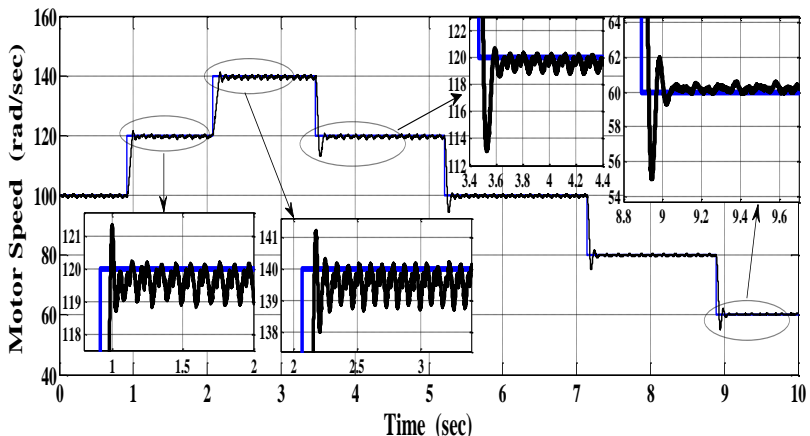

(a)

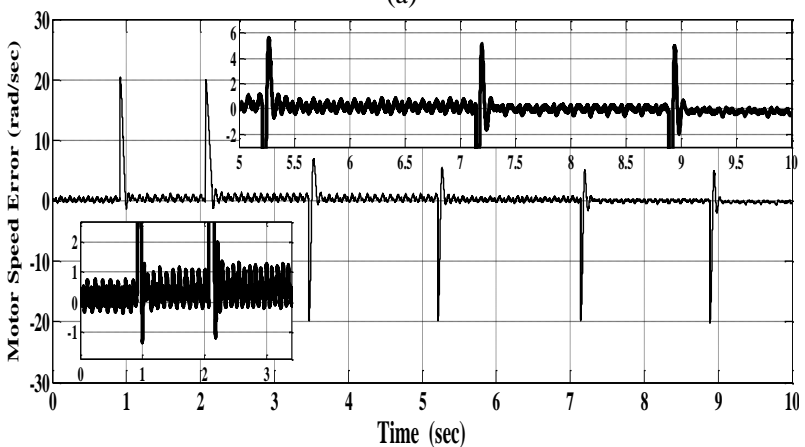

(b)

Fig.11 Experimental results of a conventional fixed PI speed controller during step change of speed: (a) Motor Speed, (b) Motor Speed Error.

\section{B. PI controller with PSO optimal gains}

The experimental results of motor speed and motor speed error in case of using PI controller with PSO optimal gains are shown in Fig.12. It is noted that, overall dynamic performances of the motor when operated at PI controller with optimal gains with PSO is better than the hand tuning, the steady-state error of speed response is zero, the overshoot and undershoot is low when speed change. We can notice the difference between them through Figs.11 and 12.

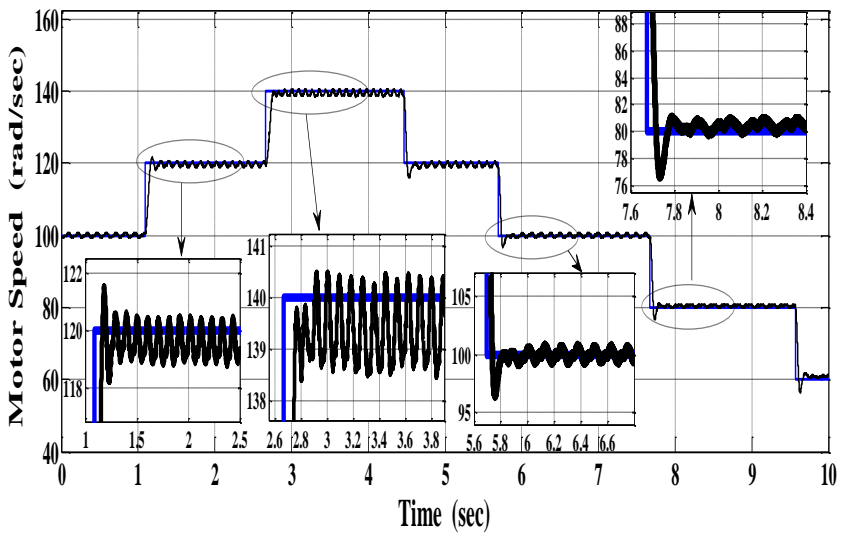

(a)

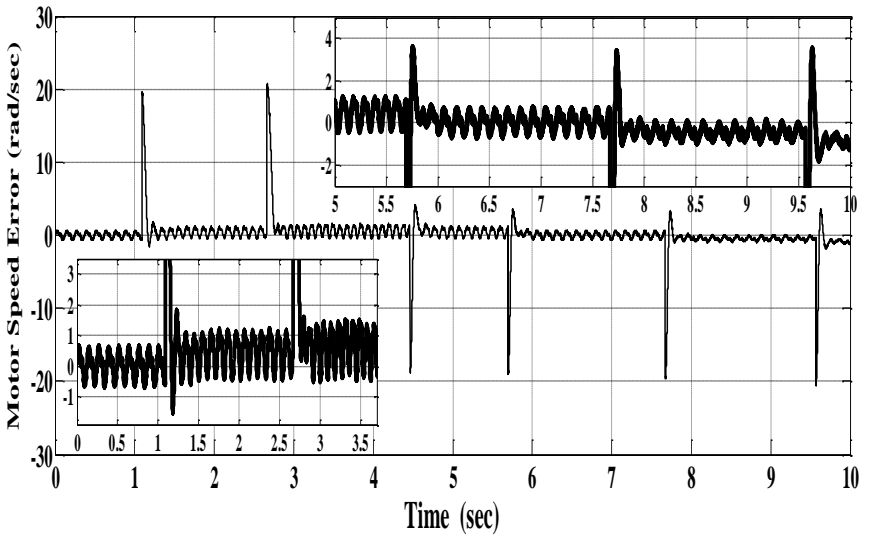

(b)

Fig.12 Experimental results of PSO-PI speed controller during step change of speed: (a) Motor Speed, (b) Motor Speed Error.

C. The Gain Schedule adaptive PI controller with PSO optimal gains

It is clear from the Fig.13 of the experimental results of GSAPI with PSO optimal gains of motor speed and motor speed error responses when loaded is better than a conventional fixed PI and PSO-PI speed controllers. There is a negligible ripple in speed response at GSAPI in comparison with two other speed controllers. It has no overshoot; no undershoots, no steady-state error and settles faster when change speed 
from 100 to $120 \mathrm{rad} / \mathrm{sec}$ and from 120 to $140 \mathrm{rad} / \mathrm{sec}$ and return again.

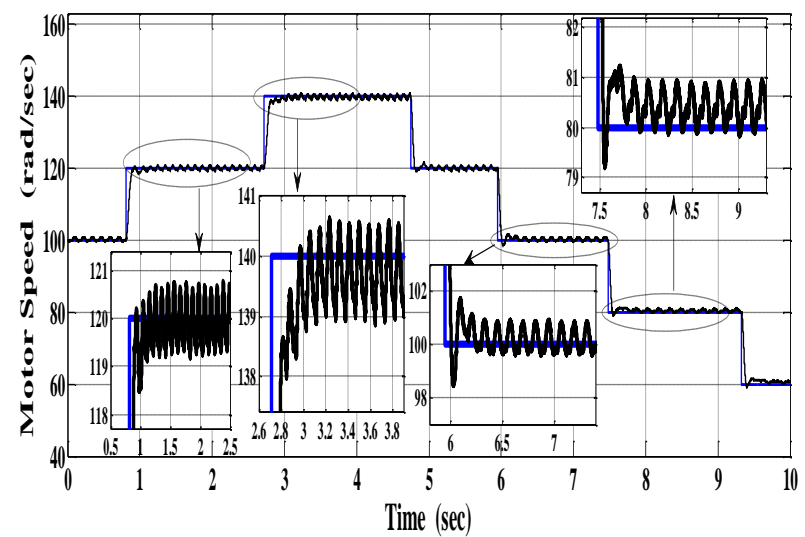

(a)

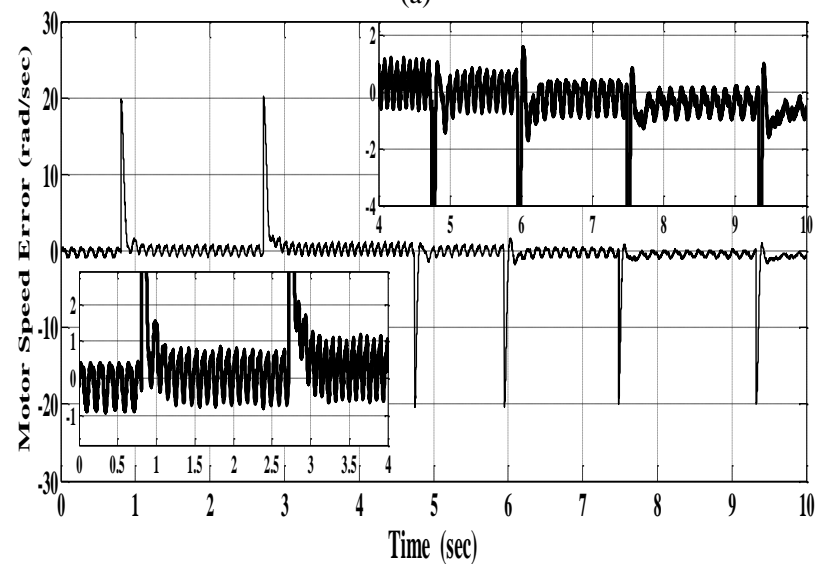

(b)

Fig.13 Experimental results using GSAPI speed controller during step change of speed: (a) Motor Speed, (b) Motor Speed Error.

The benefits of the proposed GSAPI regulator in settling time and performance are validated by comparing Fig.13 with Fig.11 and 12, which shows the performance of the same three-phase IM drive with conventional speed PI; PSO-PI and GSAPI speed controllers.

This means that the GSAPI parameters are adjusted according to the speed and load torque conditions in order to meet the control objectives and to provide high performance of the drive. The gain of the controllers can be set to control fast transient recovery and low overshoot in the dynamic response of the system. GSAPI controller improves steady-state error with little or no overshoot.

Table 3 and 4 summarizes the simulation and experimental results of all three cases of the adaptive control method GSAPI compared with the conventional fixed PI and PSO-PI without gain-scheduling control speed controllers.

\section{CONCLUSIONS}

A gain scheduling adaptive PI controller for a threephase IM drive using PSO has been presented in this paper. The three-phase IM drive system has been examined experimentally and by computer simulations with proposed controller, conventional fixed PI and PSO-PI. The gains of the proposed controller have been varied and tuned such that the drive system exhibits satisfactory transient and steady-state response under varying operating conditions. Simulation and experimental results show the effectiveness of this approach and demonstrate the usefulness of the proposed controller in high-performance drives. The proposed controller method has shown a good performance in comparison with the conventional fixed PI and PSO-PI controllers in terms of speed varied and load disturbances. Furthermore, the proposed method has characterized by simplicity, low computation time and ease of implementation. A comparison between the conventional fixed PI, PSO-PI controllers and a GSAPI one has shown the advantages of the proposed scheme.

\section{REFERENCES}

[1] G. K. Singh, K. Nam and S. K. Lim, "A Simple Indirect Field-Oriented Control Scheme for Multiphase Induction Machine" IEEE Transactions on Industrial Electronics Society, Vol. 52, No. 4, pp. 1177 - 1184 Aug 2005.

[2] R. Thangaraj, Th. R. Chelliah, M. Pant and A. Abraham, C. Grosan, "Optimal gain tuning of PI speed controller in induction motor drives using particle swarm optimization", Oxford Journals, Mathematics \& Physical Sciences, Logic Journal of the IGPL, Vol 19, No. 2, pp. 343-356, July 2010.

[3] S. Subramanian, R. Bhuvaneswari and V.P. Sakthivel, "An Improved Particle Swarm Optimization for Induction Motor Parameter Determination" International Journal of Computer Applications, Vol. 1, No. 2, pp. 62-67, 2010.

[4] V. Chitra and R. S. Prabhakar, "Induction Motor Speed Control using Fuzzy Logic Controller", World Academy of Science, Engineering and Technology 23, pp. 17-22, 2006.

[5] M. S. Zaky and E. M. Ismaeil "Gain Scheduling Adaptive PI Control of Hybrid Stepper Motor Drives Stepper Motor Drives" Electrical Power Components and systems, No. 121, pp. 85-91, Dec 2010. 
[6] A. Besharati, W. Lo and K. M Tsang, "Self-tuning PID controller using Newton-Raphson Search Method", IEEE Transactions on Power Electronics. Vol. 44, No. 5, pp. 717-725, Oct 1997.

[7] Y. del Valle, G.K. Venayagamoorthy, S. Mohagheghi, J.C. Hernandez, and R.G. Harley, "Particle Swarm Optimization: Basic Concepts, Variants and Applications in Power Systems", IEEE Transactions on Evolutionary Computation, Vol. 12, No. 2, pp. 171-195, Apr 2008.

[8] M.A. Porta García, O. Montiel, O. Castillo and R. Sepúlveda. "Optimal Path Planning for Autonomous Mobile Robot Navigation Using Ant Colony Optimization and a Fuzzy Cost Function Evaluation" Springer-Verlag Berlin Heidelberg, Analysis and Design of Intelligent Systems using Soft Computing Techniques, pp. 790-798, 2007.

[9] R. L. Haupt and S. E. Haupt, "Practical genetic algorithms" 2nd edition, published by John Wiley \& Sons, Inc., Hoboken, New Jersey, 2004.

[10] S. Panda and N. P. Padhy, "Comparison of particle swarm optimization and genetic algorithm for FACTS-based controller design", Applied Soft Computing, ELSEVIER, Vol. 8, No. 4, pp. 1418-1427, Sep 2008.

[11] M. Peyvandi, M. Zafarani and E. Nasr, "Comparison of Particle Swarm Optimization and the Genetic Algorithm in the Improvement of Power System Stability by an SSSC-based Controller", Journal of Electrical Engineering \& Technology, Vol. 6, No. 2, pp. 182-191, 2011.

[12] H. Azarkish, S. Farahat, and S.Masoud H. Sarvari, "Comparing the Performance of the Particle Swarm Optimization and the Genetic Algorithm on the Geometry Design of Longitudinal Fin", World Academy of Science, Engineering and Technology 61, pp. 836-9, 2012.

[13] S. Panda and N. P. Padhy, "Comparison of Particle Swarm Optimization and Genetic Algorithm for TCSC-based Controller Design", International Journal of Electrical and Electronics Engineering 1:5, pp. 305-313, 2007.

[14] G. Orelind, L. Wozniak, J. Medanic, and T. Whittemore, "Optimal PID gain schedule for hydrogenerators-Design and applications," IEEE Trans. Energy Convers., Vol. 4, No. 3, pp. 300-307, Sep. 1989.

[15] M. R. Mataušek, B. I. Jefteniæ, D. M. Miljkoviæ, and M. Z. Bebiæ, "Gain scheduling control of DC motor drive with field weakening," IEEE Trans. Ind. Electron., Vol. 43, No. 1, pp. 153-162, Feb. 1996.

[16] A. Kumar, A. Kumar and S. Chanana " Genetic Fuzzy PID Controller Based on Adaptive Gain Scheduling for Load Frequency Control" IEEE, Power Electronics, Drives and Energy Systems (PEDES)\& 2010 Power India, 2010 Joint International Conference, pp. 1-8, Dec 2010.

[17] J. Talaq and F. Al-Basri, "Adaptive fuzzy gain scheduling for load frequency control," IEEE Trans. Power Syst., vol. 14, no. 1, pp. 145-150, Feb. 1999.

[18] Ch. Mademlis, and I. Kioskeridis " GainScheduling Regulator for High-Performance Position Control of Switched Reluctance Motor Drives" IEEE transactions on industrial electronics, pp. 2922-2931, Vol. 57, No. 9, Sep 2010.

[19] S. K. Panda, X. M. Zhu, and P. K. Dash, "Fuzzy gain scheduled PI speed controller for switched reluctance motor drive," in Proc. IEEE IECON, Vol. 3, pp. 989-994, Nov 1997.

[20] B. Ozpineci, L. M. Tolbert "Simulink Implementation of Induction Machine Model", IEEE conference publications, Vol. 2, pp. 728 - $734,2003$.

[21] Ae. Mahesh, Dr. Ba Singh "Vector Control of Induction Motor Using ANN and Particle Swarm Optimization" UETAE, International Journal of Emerging Technology and Advanced Engineering, pp. 480-485, Vol. 2, No. 9, Sept 2012.

[22] M. M. Eissa, G. S. Virk, A. M. AbdelGhany, E. S. Ghith, "Optimum Induction Motor Speed Control Technique Using Particle Swarm Optimization" Scientific \& Academic Publishing, International Journal of Energy Engineering, Vol. 3, No. 2, pp. 65-73, 2013.

[23] G-W. Chang, G. Espinosa-Pérez, E. Mendes, and R. Ortega "Tuning Rules for the PI Gains of FieldOriented Controllers of Induction Motors" IEEE Transactions on Industrial Electronics, pp. 592-602, Vol. 47, NO. 3, Jun 2000.

[24] E. Ozkop, H.I. Okumus "Direct Torque Control of Induction Motor Using Space Vector Modulation (SVM-DTC)" IEEE, Power System Conference, MEPCON 2008, 12th International Middle-East, pp. 368 - 372, Mar 2008.

[25] G. S. Buja, and M. P. Kazmierkowski, "Direct Torque Control of PWM Inverter-Fed AC Motors-A Survey", IEEE, Transactions on Industrial Electronics, Vol. 51, No. 4, pp. 744-757, Aug. 2004.

[26] D. Casadei, F. Profumo, G. Serra, and A. Tani "FOC and DTC: Two Viable Schemes for Induction Motors Torque Control" IEEE transactions on 
power electronics, Vol. 17, No. 5, pp. 779-787, Sep. 2002.

[27] J, Kennedy, R, Eberhart, "Particle Swarm Optimization." Proc. IEEE Int. Conf. Neural Networks. 4, pp. 1942-48, 1995.

[28] M. B. B. Sharifian, S. Galvani and M. B. Kouhshahi, "Torque fluctuations reducing in a vector-controlled induction motor drive by PI controller tuning using particle swarm optimization" IEEE, International Conference on Electrical Machines and Systems (ICEMS), pp. 1-6, Aug 2011.

[29] V.P. Sakthivel, R. Bhuvaneswari and S. Subramanian "Adaptive Particle Swarm Optimization for the Design of Three-Phase Induction Motor Considering the Active Power Loss Effect" IACSIT, International Journal of Computer and Electrical Engineering, Vol. 2, No. 4, pp. 627-636, Aug, 2010.

[30] M. Mahdavi and H. Monsef "advanced Particle Swarm Optimization used for optimal design of single-phase induction motor" (IJTPE), International Journal on, "Technical and Physical Problems of Engineering" Vol. 2, No. 1, pp. 55-59, Mar 2010.

[31] M. Pant, R. Thangaraj, and A. Abraham, "Optimal tuning of PI speed controller using nature inspired heuristics", IEEE Computer Society, In Proceedings of the Eighth International Conference on Intelligent Systems Design and Applications, pp. 420425, Nov 2008.

[32] R. Jayanthi, I. A. Chidambaram, C. Banusri "Decentralized controller gain scheduling using PSO for power system restoration assessment in a two-area interconnected power system" International Journal of Engineering, Science and Technology, Vol. 3, No. 4, pp. 14-26, 2011.

[33] M. A. Movahed, A. M. Yazdani, "Application of Imperialist Competitive Algorithm in Online PI Controller" IEEE, 2011 Second International Conference on Intelligent Systems, Modelling and Simulation (ISMS), pp. 83-87, Jan. 2011.

\section{APPENDIX}

The simulation and the experimental results for the proposed method are taken with the following specifications:
Table 2

The induction motor parameters are as follows:

\begin{tabular}{|l|l|}
\hline Rated power & $1.5 \mathrm{HP}$ \\
\hline Rated voltage & $380 \mathrm{~V}$ \\
\hline Rated current & $2-8 \mathrm{~A}$ \\
\hline No. of poles & 4 \\
\hline Stator resistance & $7.4826 \Omega$ \\
\hline Rotor resistance & $3.834 \Omega$ \\
\hline Mutual inductance & $0.4114 \mathrm{H}$ \\
\hline Stator leakage inductance & $0.0221 \mathrm{H}$ \\
\hline Rotor leakage inductance & $0.0221 \mathrm{H}$ \\
\hline Rated speed & $1400 \mathrm{rpm}$ \\
\hline Moment of inertia & $0.035 \mathrm{~kg} . \mathrm{m}^{2}$ \\
\hline Rated torque & $7.5 \mathrm{~N} . \mathrm{m}$ \\
\hline
\end{tabular}

Table 3

Gains of conventional PI and PSO-PI (off-line) controllers

\begin{tabular}{|c|c|c|c|}
\hline \multicolumn{2}{|c|}{ a conventional fixed PI } & \multicolumn{2}{c|}{ PSO-PI (off-line) } \\
\hline$K_{P c}$ & 0.5 & $K_{P p s o}$ & 1.0143 \\
\hline$K_{i c}$ & 4 & $K_{I p s o}$ & 7.1623 \\
\hline
\end{tabular}

Table 4

Gains of GSAPI speed controller

\begin{tabular}{|c|c|c|c|c|c|c|c|}
\hline $\begin{array}{c}W_{r} \\
\mathrm{rad} / \mathrm{sec}\end{array}$ & $\begin{array}{c}T_{L} \\
N . m\end{array}$ & $K_{P}$ & $K_{I}$ & $\begin{array}{c}W_{r} \\
\mathrm{rad} / \mathrm{sec}\end{array}$ & $\begin{array}{c}T_{L} \\
N . m\end{array}$ & $K_{P}$ & $K_{I}$ \\
\hline \multirow{5}{*}{150} & 0 & 2.5501 & 15.3058 & \multirow{5}{*}{50} & 0 & 1.0134 & 7.1623 \\
\hline & 1.75 & 2.7851 & 17.0301 & & 1.75 & 5.3254 & 28.3254 \\
\hline & 3.5 & 2.9853 & 17.805 & & 3.5 & 5.4408 & 30.4563 \\
\hline & 5.25 & 2.9853 & 17.8315 & & 5.25 & 5.5542 & 30.5468 \\
\hline & 7 & 3.0214 & 17.9094 & & 7 & 5.9898 & 33.8245 \\
\hline \multirow{5}{*}{100} & 0 & 2.6899 & 15.9958 & \multirow{5}{*}{37.5} & 0 & 3.0578 & 19.0623 \\
\hline & 1.75 & 2.5035 & 18.101 & & 1.75 & 6.1578 & 30.9554 \\
\hline & 3.5 & 2.5954 & 16.8795 & & 3.5 & 6.3212 & 31.0663 \\
\hline & 5.25 & 2.7120 & 16.9515 & & 5.25 & 6.4625 & 31.6653 \\
\hline & 7 & 2.9225 & 17.0094 & & 7 & 6.6045 & 35.0658 \\
\hline \multirow{5}{*}{75} & 0 & 3.5486 & 23.2645 & \multirow{5}{*}{-100} & 0 & 0.9073 & 5.6958 \\
\hline & 1.75 & 4.0852 & 23.3209 & & 1.75 & 2.0254 & 9.5487 \\
\hline & 3.5 & 4.6025 & 23.6825 & & 3.5 & 4.7853 & 15.4015 \\
\hline & 5.25 & 4.6320 & 23.8315 & & 5.25 & 6.5123 & 35.7714 \\
\hline & 7 & 4.6457 & 23.9094 & & 7 & 7.2105 & 38.5478 \\
\hline
\end{tabular}

